\title{
ARTICLE
}

\section{Transcription factor 7-like 1 dysregulates keratinocyte differentiation through upregulating lipocalin 2}

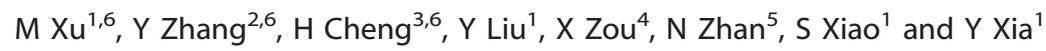

Recent studies strongly suggested that transcription factor 7-like 1 (Tcf7l1, also known as Tcf3) is involved in the differentiation of several types of cells, and demonstrated that Tcf7l1 modulates keratinocytes physiologically through regulating lipocalin 2 (LCN2), a key regulator of cell differentiation. To reveal the potential role of Tcf7l1 in the dysregulation of keratinocyte differentiation, both Tcf7l1 and LCN2 were determined in a variety of skin disorders. The in vitro effect of Tcf7l1 on keratinocyte differentiation was studied by culturing SCC-13 cells, and the human foreskin keratinocytes (HFKs) that were transfected with vectors for overexpressing human papillomavirus E6/E7 or Tcf7I1 genes. We found that both Tcf7I1 and LCN2 were highly expressed in those diseases characterized by defective keratinocyte differentiation (especially psoriasis vulgaris, condyloma acuminatum, squamous cell carcinoma, etc). Moreover, compared with control HFKs, SCC-13 cells and E6/E7-harboring HFKs expressed more Tcf7l1 and LCN2. Tcf7I1 siRNA transfection decreased LCN2 but increased involucrin and loricrin in HFKs under calcium stimuli. Conversely, Tcf7I1 overexpression in SCC-13 cells or vector-transfected HFKs induced lower involucrin and loricrin expression and less keratinocyte apoptosis, both of which, however, were partially abrogated by LCN2 siRNA or neutralizing anti-LCN2 antibody. Interestingly, the Tcf7l1 expression in HFKs correlated positively with the MMP-2 level, and the inhibition of MMP-2 decreased the LCN2 level and even attenuated the effect of Tcf7l1 on LCN2 expression. Therefore, Tcf7l1 dysregulates keratinocyte differentiation, possibly through upregulating the LCN2 pathway in an MMP-2 mediated manner. Elucidating the interaction between Tcf7I1 and LCN2 may help understand disordered cell differentiation in some skin diseases.

Cell Death Discovery (2016) 2, 16028; doi:10.1038/cddiscovery.2016.28; published online 25 April 2016

\section{INTRODUCTION}

Transcription factor 7-like 1 (Tcf7l1), also called the high mobility group box transcription factor Tcf3, is a key regulatory protein that institutes transcriptional programs for cell development and proliferation. $^{1-3}$ Tcf7l1 is expressed by a variety of cell types, including neural and follicular stem cells, epidermal cells and cancer cells of multiple origins. ${ }^{2,4-7}$ Through direct binding to multiple gene sites and interaction with proteins, Tcf7l1 regulates Wnt- $\beta$-catenin and c-Myc signaling, which further functions in the differentiation, proliferation and malignancy of different cells. ${ }^{8,9}$ Recently, Tcf7l1 activation was found in cutaneous keratinocytes, especially those with a poor differentiation status. ${ }^{4,8,10}$ Induction of TCF7L1 in mouse epidermal progenitor cells is sufficient to abrogate terminal differentiation and maintain an undifferentiated cell fate. ${ }^{4}$ Moreover, Tcf7l1 is upregulated in skin wounds, and then accelerates keratinocyte migration and skin wound healing through regulation of lipocalin 2 ( $L C N 2$, or neutrophil gelatinaseassociated lipocalin). ${ }^{11}$ Many studies have demonstrated that LCN2 signals play an important role in cell differentiation. ${ }^{12-14}$ Therefore, Tcf7l1 signaling is pivotal in the modulation of keratinocyte behaviors especially differentiation.

LCN2 is an autocrine cytokine functioning through interaction with the LCN2 receptor that is expressed in various cells. By multiple mechanisms, LCN2 is involved in cell differentiation. LCN2 inhibits the nuclear factor $\kappa \mathrm{B}$ pathway, ${ }^{14}$ activates the Met/FAK cascade, ${ }^{15}$ upregulates mesenchymal markers but downregulates the epithelial marker E-cadherin, ${ }^{16}$ and also gives rise to cells with a more immature phenotype. ${ }^{17}$ Moreover, LCN2 is strongly expressed in cancer cells and correlates negatively with the differentiation grade of tumors. ${ }^{15,16,18}$ LCN2 forms complex with both MMP-2 and MMP-9 in cancer cells, ${ }^{19-21}$ which are also suggested to be functional in regulating cell differentiation. ${ }^{22,23}$ Interestingly, LCN2 expression is promoted in keratinocytes upon HPV infection that confers keratinocytes property of poor differentiation. ${ }^{24}$ LCN2 even fluctuates with the differentiation degree of keratinocytes and preferentially appears in differentiating keratinocytes or some skin diseases with parakeratotic epidermis. ${ }^{25,26}$ All these findings strongly indicated LCN2 as a marker for dysregulated keratinocyte differentiation in skin. However, the upstream regulation of LCN2 signals, especially that involves cell differentiation, remained unclear to date.

The dysregulated differentiation of keratinocytes is commonly seen in several skin disorders including psoriasis, warts and squamous cell carcinoma (SCC). To unveil the mechanisms related to such dysregulation is important in the development of novel therapeutic approaches for the treatment of these diseases. Considering the facts that Tcf7l1 closely modulates the behaviors of keratinocytes and regulates the LCN2 pathway under certain condition, ${ }^{11}$ we presumed

\footnotetext{
${ }^{1}$ Department of Dermatology, The Second Affiliated Hospital, School of Medicine, Xi'an Jiaotong University, Xi'an 710004, China; ${ }^{2}$ Intensive Care Unit, China Gezhouba Group Central Hospital, The Third Clinical Medical College of China Three Gorges University, Yichang, China; ${ }^{3}$ Department of Medicine, The Second Affiliated Hospital, School of

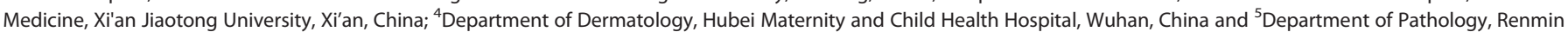
Hospital of Wuhan University, Wuhan, China.

Correspondence: Y Xia (xiayumin1202@163.com)

${ }^{6}$ These authors contributed equally to this work.

Received 30 March 2016; accepted 1 April 2016; Edited by A Rufini
} 
that Tcf7l1 also play a role in the dysregulation of keratinocyte differentiation. Therefore, the aim of this study was to investigate the expression Tcf7l1 in skin diseases and the possible mechanism underlying its regulation of keratinocyte differentiation.

\section{RESULTS}

Both Tcf7I1 and LCN2 are highly expressed in skin diseases featuring dysregulated keratinocyte differentiation

By immunohistochemistry, both Tcf7l1 and LCN2 were strongly expressed in psoriasis vulgaris, verrucous epidermal nevus, condyloma acuminatum and SCC (Broders' grade I) while negative or slight expression was seen with normal skins, seborrheic keratosis, Bowenoid papulosis and basal cell carcinoma (BCC) (Figure 1a). In the four diseases that showed stronger Tcf7l1 staining, western blotting revealed higher levels of Tcf7l1, which were usually accompanied by elevated LCN2 expression (Figure 1b). Moreover, we determined tissue mRNA expression of these two proteins in the samples, and found a positive correlation between them (Figure 1c). Pigmented nevus also exhibited both Tcf7l1 and LCN2 overexpression, which was predominant in melanocytes underneath the epidermis but not in keratinocytes (Figures $1 \mathrm{a}$ and $\mathrm{b}$ ).

Tcf7l1 expression was even evaluated in SCC tissues that were classified based on cell differentiation. In both protein and mRNA levels, Tcf7l1 increased in terms of Broders' classification grade (Supplementary Figure S1).

Both Tcf7I1 and LCN2 increase in keratinocyte-originated cells with differentiation dysregulation

The expression of Tcf7l1 and LCN2 was investigated further in cells that differed in differentiation. Immunofluorescent detection showed that, compared with control (transfected with blank vector) human foreskin keratinocytes (HFKs), the SCC-13 cells or HPV16 E6/ E7-transfected HFKs expressed more Tcf7l1 and LCN2 (Figure 2a), which was even quantitatively confirmed by flow cytometry (Figures $2 \mathrm{~b}$ and $\mathrm{c}$ ). Proteins were extracted from these cells, displaying elevated levels of Tcf7l1 and LCN2 in the SCC-13 and E6/ E7-positive cells (Figures $2 \mathrm{~d}$ and e). The differences in differentiation between these cells were verified by assessing two specific markers (involucrin and loricrin), showing lower levels in E6/E7-positive cells and SCC -13 cells when compared with control HFKs (Supplementary Figure S2). Moreover, HFKs were induced for differentiation by calcium stimuli, followed by mRNA and protein extraction at different time points. The results showed that Tcf7l1 and LCN2 expression increased with incubation time of calcium (Figure 3).

Tcf7l1 depletion represses LCN2 expression during differentiation of HFKs

To demonstrate the direct effect of Tcf7l1 on LCN2 expression and keratinocyte differentiation, HFKs were transfected with Tcf7l1 siRNA and then stimulated with calcium chloride (1.2 mM, 7 days). It was found that Tcf7l1 but not control siRNA reduced Tcf7l1 synthesis substantially (Supplementary Figure S3). The intracellular and soluble (in culture supernatants) LCN2 was determined by western blot and enzyme-linked immunosorbent assay (ELISA), showing remarkable reduction upon Tcf7l1 siRNA transfection (Figures $4 a$ and b). Flow cytometry further confirmed such reduction of intracellular LCN2 (Supplementary Figure S3). Despite of siRNA transfection, calcium stimuli enhanced LCN2 expression in HFKs (Figures $4 a$ and b). Moreover, both immunofluorescence and western blot demonstrated more expression of involucrin and loricrin by the HFKs transfected with Tcf7l1 siRNA (Figures 4c-e). Consistently, such increase in involucrin and loricrin expression was also verified in these HFKs by quantitative real-time polymerase chain reaction (qRT-PCR) (Supplementary Figure S3).
Tcf7l1 overexpression promotes LCN2 level but inhibits apoptosis of HFKs undergoing differentiation

HFKs were transfected with a lentiviral vector to overexpress Tcf7l1 (Supplementary Figure S4), followed by calcium stimulation. By qRT-PCR and western blot, it was found that LCN2 increased in Tcf7l1-overexpressing HFKs when compared with the non-Tcf7l1transfected HFKs (Figures $5 \mathrm{a}$ and $\mathrm{b}$ ). Moreover, compared with the same control, Tcf7l1-transfected HFKs exhibited a significant decrease in apoptosis while cell proliferation was not affected (Figures $5 c$ and d). Additionally, Tcf7l1-transfected HFKs exhibited lower mRNA levels of involucrin, loricrin and caspase-14 when compared with non-Tcf7l1-transfected HFKs, although calcium induced expression of these markers (Figure 5e).

\section{LCN2 inhibition abrogates effect of Tcf7l1 on keratinocyte} differentiation

Since both Tcf7l1- and E6/E7-vector-transfected HFKs overexpressed Tcf7l1 (Figure 2), LCN2 signals were inhibited in these cells by LCN2 siRNA or neutralizing anti-LCN2 antibody. By western blot, LCN2 inhibition enhanced both involucrin and loricrin expression in Tcf7l1-overexpressing HFKs (Figures 6a-d), which was primarily suppressed in these cells when compared with control HFKs (Supplementary Figure S2 and Figure 5e). Furthermore, the treatment with LCN2 siRNA prompted keratin 1 expression in the Tcf7l1 vector-transfected HFKs (Figures $6 \mathrm{e}$ and f). Such effect of LCN2 siRNA transfection on these differentiation markers was also reflected by qRT-PCR analysis (Supplementary Figure S4). Meanwhile, LCN2 siRNA had no effect on the expression of Tcf7l1 mRNA in these HFKs (data not shown). Consistently, LCN2 siRNA recovered both cell apoptosis (Figure 6g) and keratin 1 expression (Supplementary Figure S4) in HFKs that were suppressed by Tcf7l1 overexpression.

\section{MMP-2 mediates the enhancement effect of Tcf7l1 on LCN2} expression

The proteins of MMP-2 and MMP- 9 were determined by western blot in SCC-13 cells and Tcf7l1- or E6/E7-transfected HFKs. The results showed that both MMP-2 and MMP-9 levels increased with Tcf7l1 expression (Figure 7a). However, the MMP-2 level was more affected by Tcf7l1, leading to an increase in the MMP-2/MMP-9 ratio in Tcf7l1-overexpressing cells (Figure $7 \mathrm{~b}$ ). In addition, the transfection of MMP-2 but not control siRNA significantly reduced LCN2 production in Tcf7l1-overexpressing HFKs (Figure 7c). Consistently, the mRNA levels of Tcf7l1, MMP-2, MMP-9 and LCN2 showed a similarity to the proteins in these cells (Supplementary Figure S5).

The MMPs/LCN2 complexes in cell lysates were detected by immunoprecipitation and then determined by western blot. Interestingly, the anti-LCN2 IgG-precipitated samples revealed more MMP-2 and higher MMP-2/MMP-9 ratio in the Tcf7l1overexpressing HFKs when compared with control HFKs (Figure 7d).

\section{DISCUSSION}

In the present study, we found that Tcf7l1 and LCN2 are overexpressed in the keratinocytes and skin diseases that are characterized by dysregulated differentiation. Moreover, LCN2 expression increases with the Tcf7l1 level in HFKs undergoing differentiation, and decreases significantly upon Tcf7l1 depletion. Furthermore, Tcf7l1 overexpression induces suppression of both cell apoptosis and differentiation marker expression, which can be partially abrogated by LCN2 inhibition. Finally, Tcf7l1 overexpression induces more MMP-2 than MMP-9 in HFKs, and MMP-2 inhibition represses the LCN2 level. Therefore, these results convincingly demonstrated that Tcf7l1 plays a pivotal role in the 

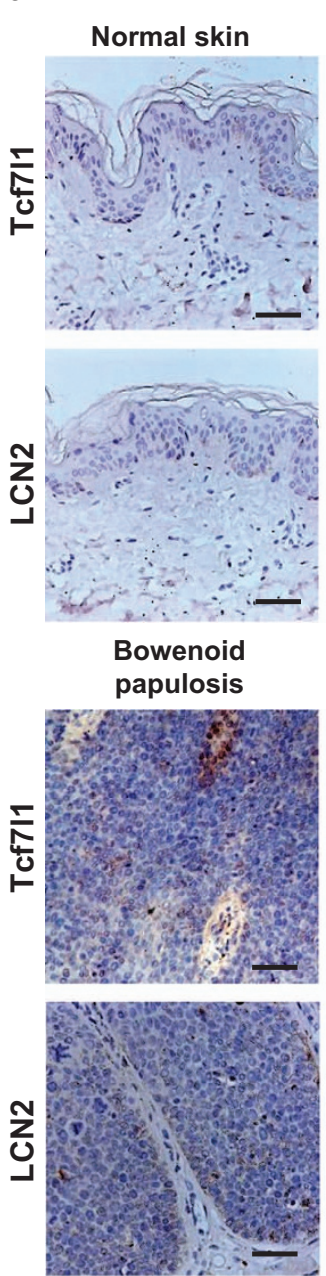

b
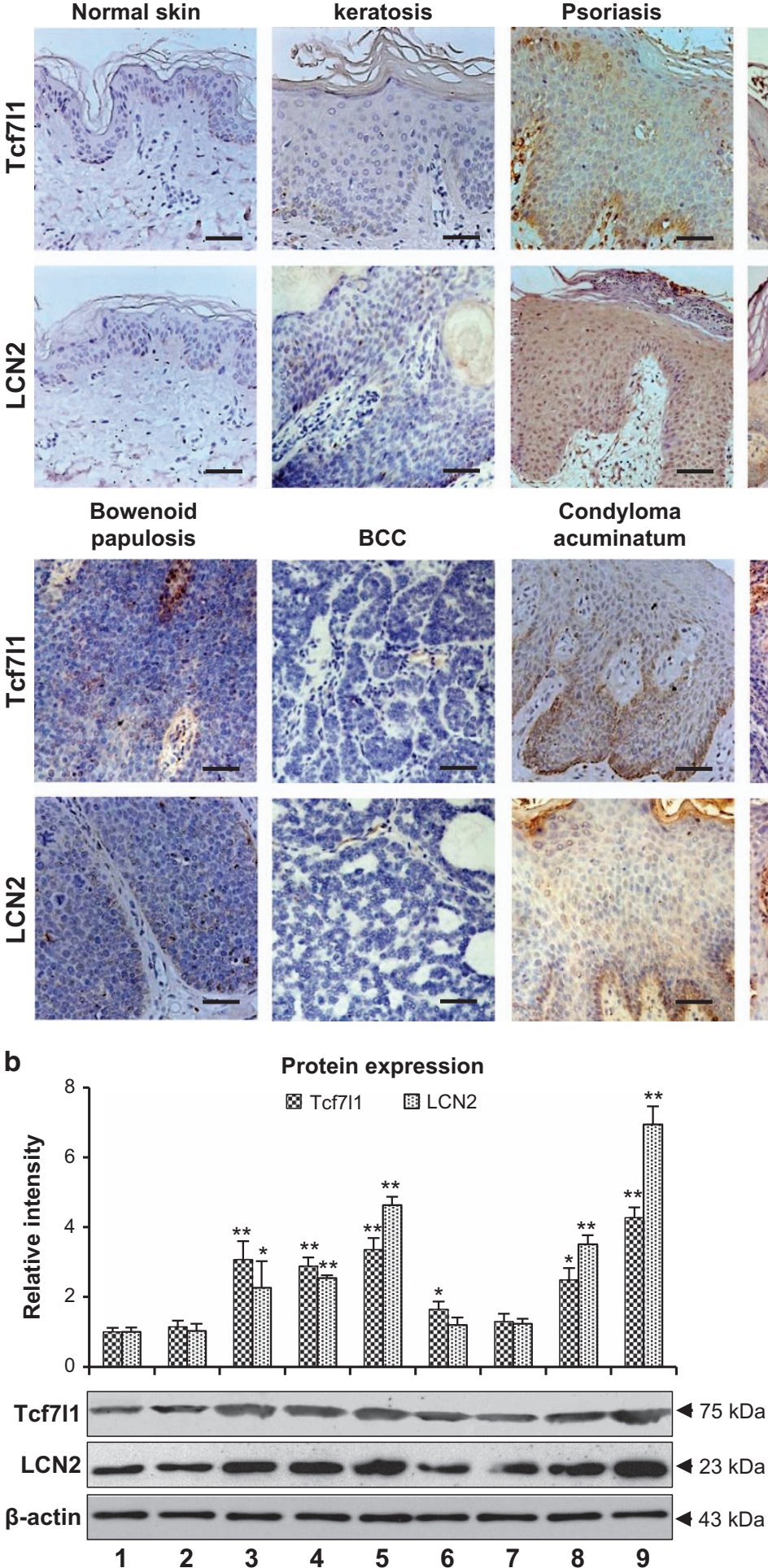

BCC
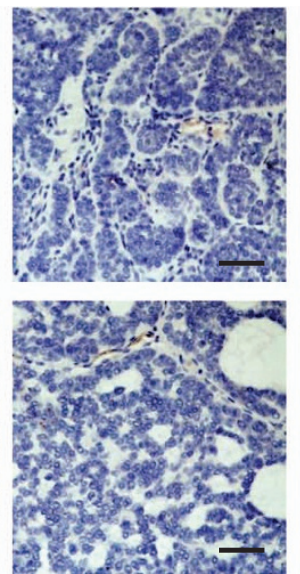

Protein expression
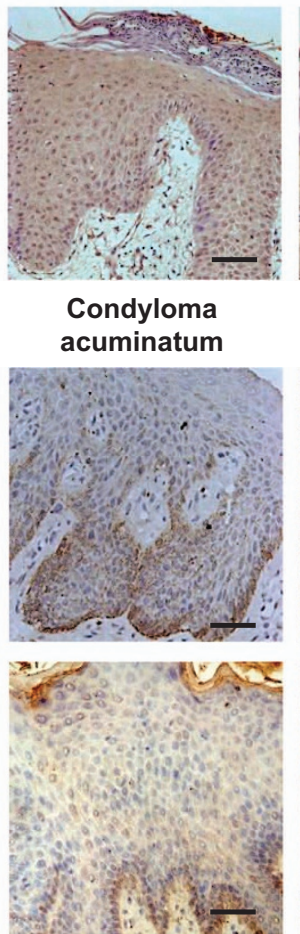

Condyloma

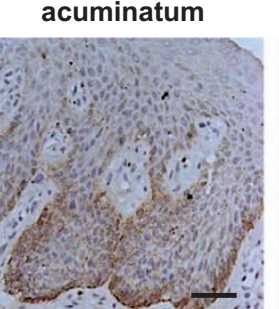

Seborrheic
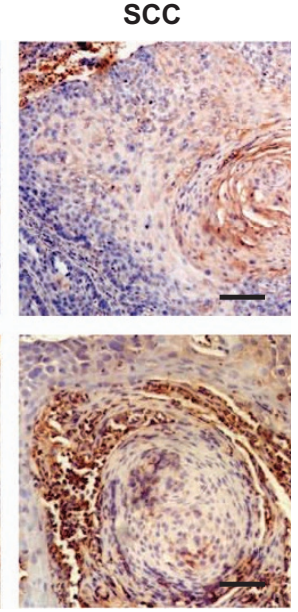

C

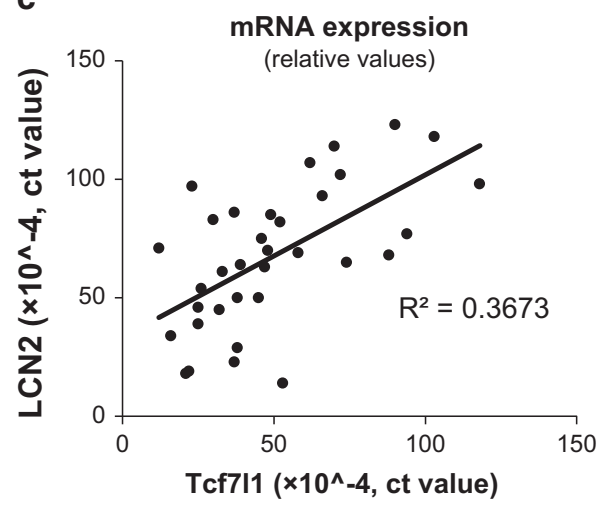

Figure 1. Tcf7l1 and LCN2 expression in skin diseases. (a) By immunohistochemistry, Tcf7l1 and LCN2 were stained in normal skin ( $n=4$ ), seborrheic keratosis $(n=4)$, psoriasis vulgaris $(n=5)$, verrucous epidermal nevus $(n=3)$, pigmented nevus $(n=4)$, Bowenoid papulosis $(n=3)$, BCC $(n=4)$, condyloma acuminatum $(n=4)$ and SCC (Broder's grade I, $n=3)$. (b) By western blot, the Tcf7l1 and LCN2 proteins were detected individually in all tissue lysates, followed by a quantitation of band intensities using ImageJ. Numbers of 1 to 9 indicate the normal skin and eight diseases shown in (a) in order. ${ }^{*} P<0.05,{ }^{*} P<0.01$, compared with normal skins accordingly. Data are expressed as mean \pm S.E.M. Statistical differences were tested with one-way ANOVA followed by a two-tailed $t$-test. (c) The mRNA expression levels were determined individually, followed by the linear correlation between the Tcf7l1 and LCN2 values $(n=34, P<0.05)$. Linear regression was done for the correlation between the mRNA values of Tcf7I1 and LCN2. Representative images are shown. Scale bar $=50 \mu \mathrm{m}$. 
a
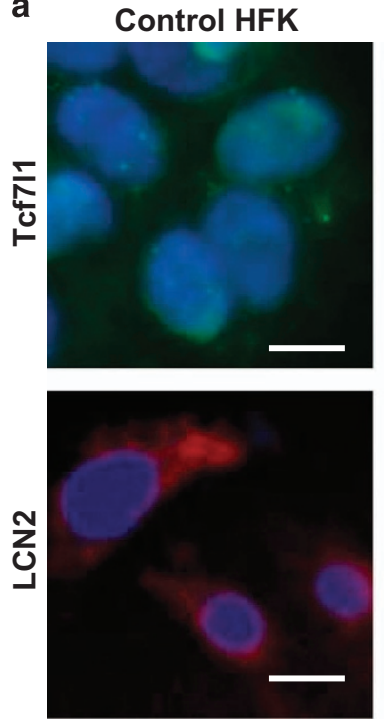

b

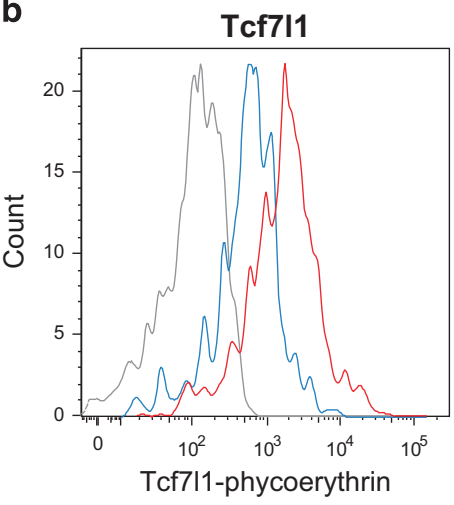

E6/E7-HFK
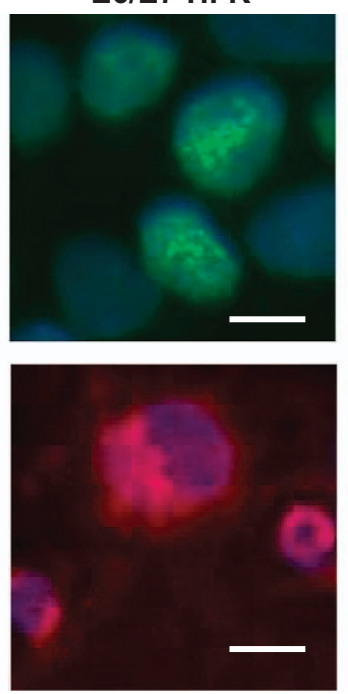

LCN2

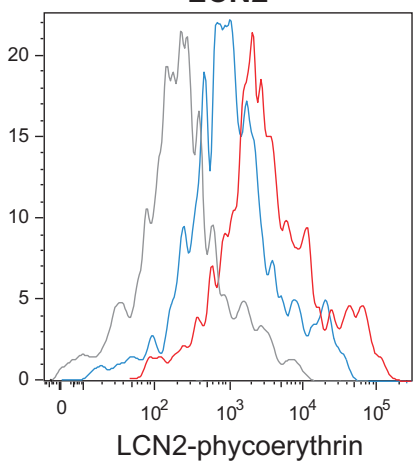

c
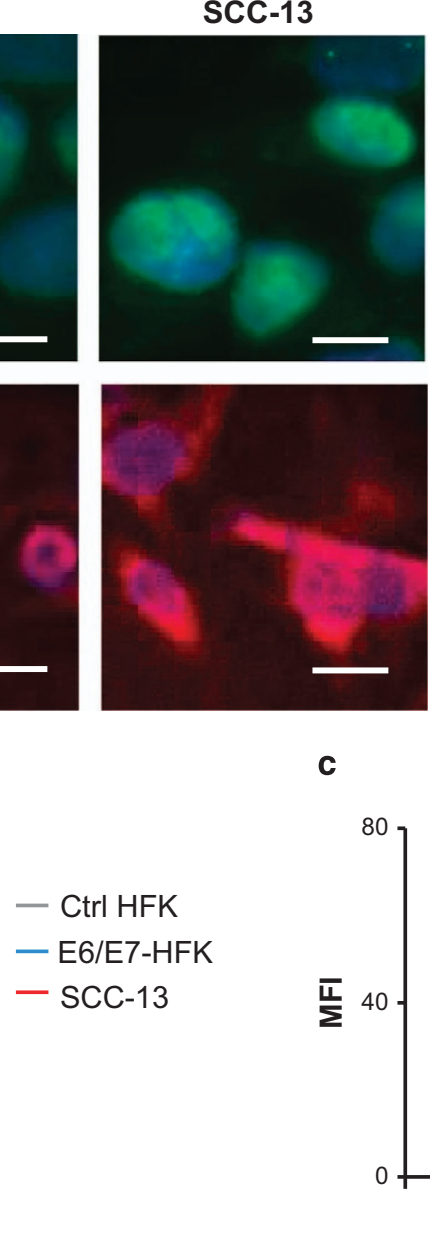

Flow cytometry

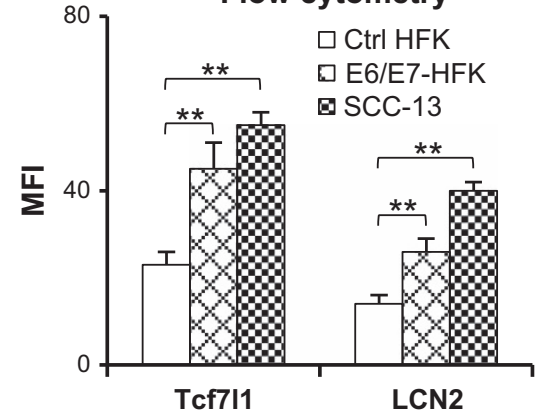

d

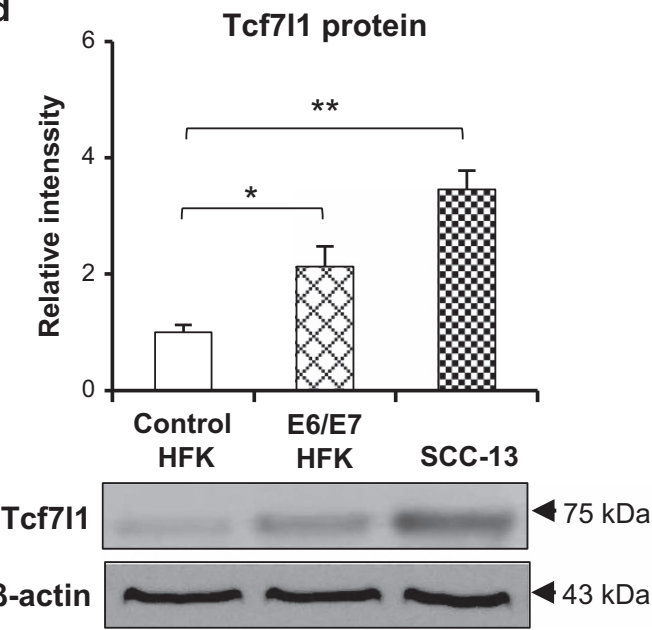

e

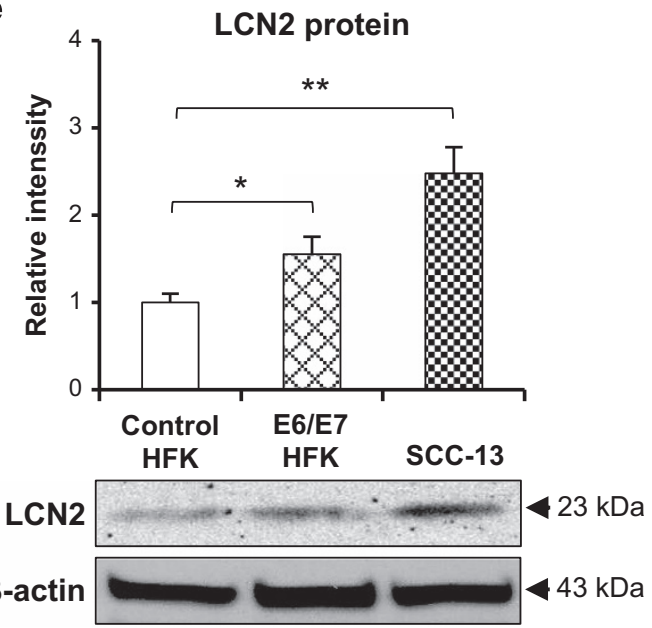

Figure 2. Tcf7l1 and LCN2 expression in cells in vitro. Control HFKs (transfected with blank vector), E6/E7 gene-transfected HFKs, and SCC-13 cells were cultured in vitro. (a) Immunofluorescence showed the strongest Tcf7l1 (green) and LCN2 (red) staining in SCC-13 cells, followed by E6/E7-transfected and control HFKs in order. (b and c) Flow cytometry confirmed more Tcf7l1 and LCN2 expression in SCC-13 cells and E6/E7transfected HFKs when compared with control HFKs. MFI, mean fluorescent intensity. (d and e) Western blot revealed the highest levels of Tcf7I1 (d) and LCN2 (e) in SCC-13 cells. Data show mean \pm S.E.M. of triplicate cultures $(n=3)$. Statistical differences were tested with one-way ANOVA followed by a two-tailed $t$-test. Representative images are shown. Scale bar $=5 \mu \mathrm{m}$. ${ }^{*} P<0.05 ;{ }^{* *} P<0.01$.

dysregulation of keratinocyte differentiation through upregulating the LCN2 pathway.

Our results are consistent with previous reports. Lee et al. ${ }^{25}$ found stronger staining of LCN2 in lichen planus, pityriasis rubura pilaris, keratoacanthoma and SCC than in pityriasis rosea and BCC. Mallbris et al. demonstrated a higher LCN level in psoriasis than in healthy controls. ${ }^{26}$ Nguyen et al. ${ }^{4}$ even found that Tcf7l1 induces LCN2 gene expression in epidermis isolated from mice. In the 
a
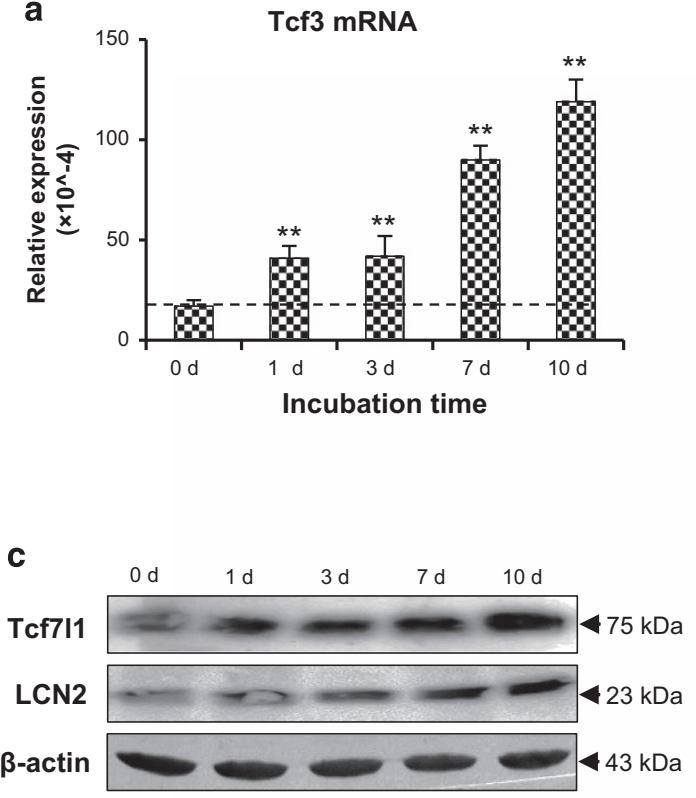

\section{b}

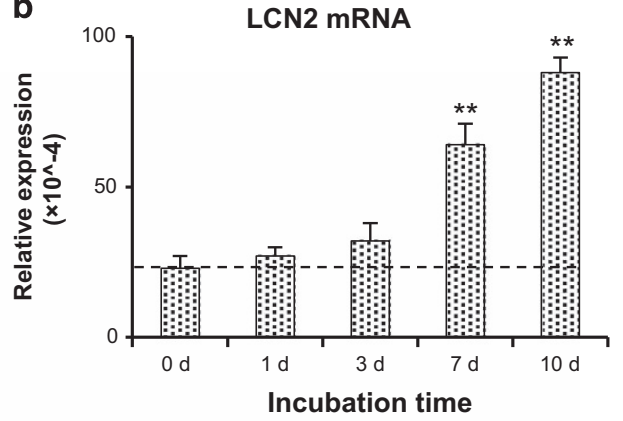

d

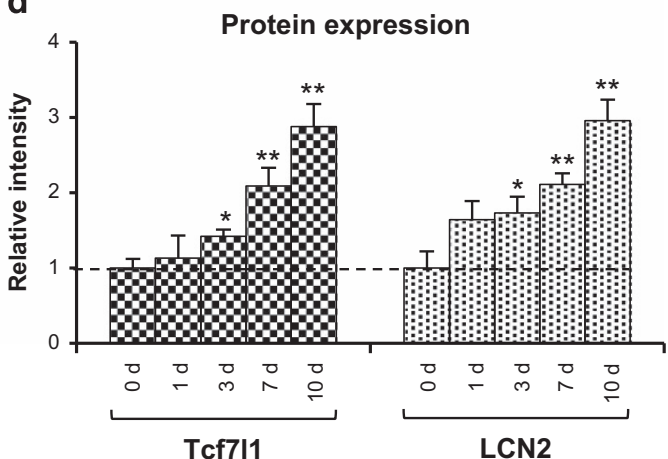

Figure 3. Tcf7l1 and LCN2 expression in keratinocytes undergoing differentiation. HFKs were cultured in vitro with the addition of calcium $(1.2 \mathrm{mM})$. (a and $\mathbf{b})$ The mRNA levels of Tcf7l1 (a) and LCN2 (b) were determined in HFKs that were harvested at different time points. (c and d) Western blot was performed with protein extracts of HFKs for Tcf7l1 and LCN2 expression (c), followed by quantitation of band intensities with ImageJ (d). Data show mean \pm S.E.M. of triplicate cultures $(n=3)$. Statistical differences were tested with one-way ANOVA followed by a two-tailed $t$-test. Representative images are shown. ${ }^{*} P<0.05$, ${ }^{* *} P<0.01$, compared with the values on day 0 accordingly.

present study, we further supported these findings by not only providing quantitative data but also showing more LCN2 expression in verrucous epidermal nevus and condyloma acuminatum, which both harbor dysregulation of keratinocyte differentiation (parakeratosis) as other disorders above. In addition, we verified a positive correlation between Tcf7l1 and LCN2 expression in these tissues. Impressively, Tcf7l1 increases in terms of Broders' classification grade of SCC, further indicating involvement of Tcf7l1 in cell differentiation. The overexpression of Tcf7l1 and LCN2 in melanocytes of pigmented nevus suggests an additional function of the Tcf7I1-LCN2 axis, which should be elucidated in other studies.

In this study, HFKs were induced for differentiation by calcium stimuli. It had been found that LCN2 is calcium inducible in keratinocytes and increases with stimulation time. ${ }^{25}$ We saw elevated Tcf7I1 and LCN2 expression in HFKs under calcium stimulation, which seems to bring doubt on the effect of Tcf7l1 on keratinocyte differentiation since involucrin and loricrin, two terminal differentiation markers, ${ }^{27}$ are also enhanced upon calcium stimulation. ${ }^{28}$ We speculated that HFKs undergoing differentiation synthesize involucrin and loricrin naturally, which, however, induce Tcf7l1 and LCN2 expression in a feedback manner. In other words, Tcf7l1 and LCN2 control the overfunction of involucrin and loricrin in keratinocytes during differentiation. Such speculation was verified by the facts that in HFKs under calcium stimulation, Tcf7l1 overexpression reduces the levels of involucrin, loricrin and caspase-14 while Tcf7l1 depletion promotes involucrin and loricrin production.

As specific markers for cell differentiation, involucrin, loricrin and caspase-14 increase in keratinocytes during differentiation $^{27,29}$ but decrease during dysregulation of keratinocyte differentiation. ${ }^{30,31}$ Our results showed an enhancement effect of Tcf7l1 depletion on these markers as well as a reverse effect of Tcf7l1 overexpression on them, unveiling negative regulation of
Tcf7l1 in keratinocyte differentiation. Another important feature of differentiation dysregulation in keratinocytes is the decrease in apoptosis while proliferation may change or not. ${ }^{32,33}$ We found that Tcf7l1 overexpression inhibits apoptosis of HFKs but shows no effect on cell proliferation, also reflecting the role of Tcf7l1 in dysregulating differentiation. Additionally, the blockade of LCN2 downregulates the expression of keratin 1 in calcium-stimulated HFKs, providing more evidence in support of our speculation.

In both skin tissues and keratinocytes that have different status of differentiation, LCN2 expression fluctuates with the Tcf7I1 level, revealing a positive correlation between the two proteins. Importantly, the inhibition of LCN2 through the siRNA approach or anti-LCN2 antibody abrogates the effect of Tcf7l1 on keratinocyte differentiation, further confirming a LCN2 mediation in Tcf7l1-dysregulated keratinocyte differentiation. Considering many studies that demonstrated the critical role of LCN2 in suppressing cell differentiation, ${ }^{12,14,18}$ we deduced that the Tcf7l1-LCN2 axis is effective in dysregulating keratinocytes.

An interesting finding in this study was that Tcf7l1 induces high level of MMP-2 and enhances the MMP-2/MMP-9 ratio in HFKs. It has been known that both MMP-2 and MMP-9 are involved in cell differentiation. ${ }^{34-36}$ However, MMP-9 promotes terminal differentiation of keratinocytes while MMP-2 counters the effect of MMP-9 and prevents keratinocytes from such differentiation. ${ }^{37}$ Previous studies demonstrated that the complexes of LCN2 plus MMP-2 or MMP-9 form in tissues, ${ }^{20,38,39}$ and stabilize the partners by protecting autodegradation. ${ }^{40,41}$ Additionally, we found that Tcf7l1 enhances MMP-2 bound by LCN2, and MMP-2 inhibition reduces effect of Tcf7l1 on the expression of LCN2 and some markers for keratinocyte differentiation. Therefore, the prevailing MMP-2 expression in Tcf7l1-overexpressing HFKs may favor LCN2 upregulation in a feedback manner, and subsequently leads to the dysregulation of keratinocyte differentiation. Currently, the precise 
a

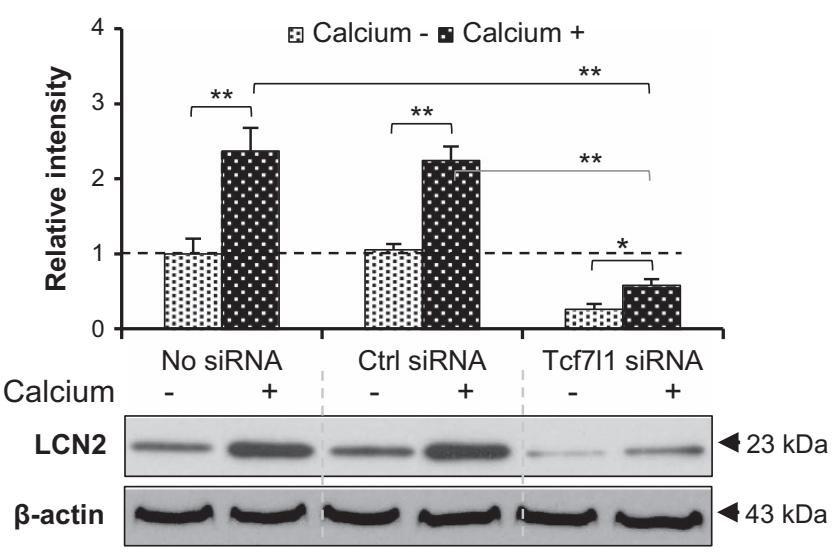

b

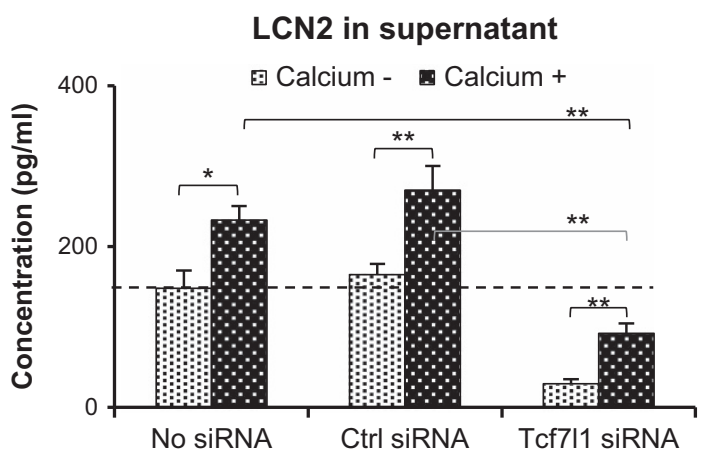

c
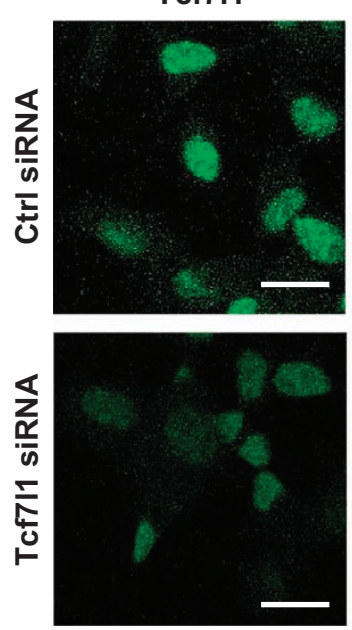

d

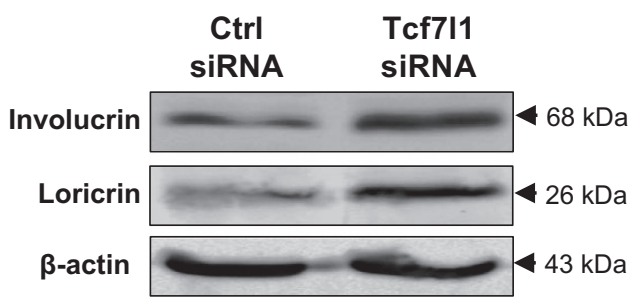

Involucrin
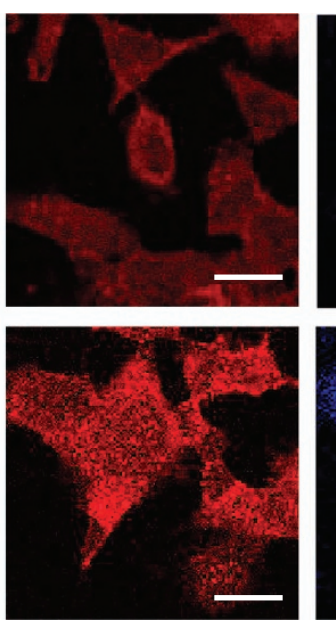

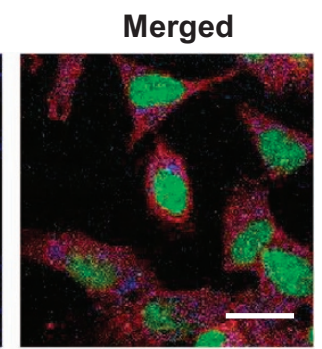

Loricrin
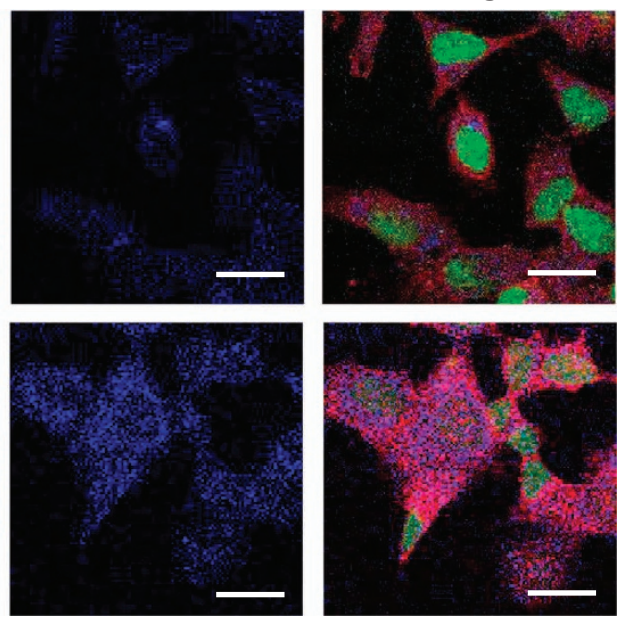

e

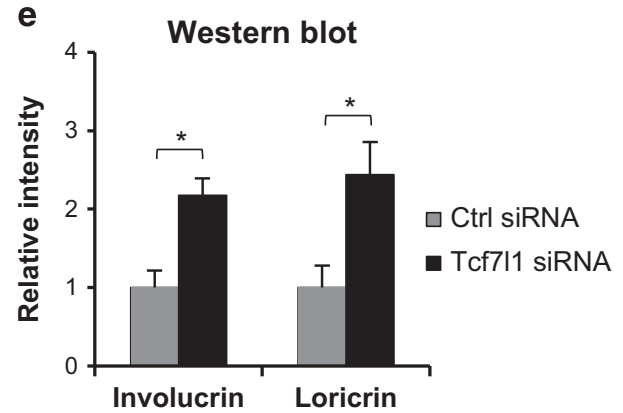

Figure 4. The effect of Tcf7l1 depletion on LCN2 expression in HFKs. HFKs were stimulated with calcium chloride (1.2 mM, 7 days) after siRNA transfection. (a and b) Intracellular (a) and soluble (b) LCN2 levels were evaluated by western blot and ELISA, respectively. (c) By immunofluorescence, the expression of involucrin and loricrin were detected in HFKs that were transfected with Tcf7l1 or control siRNA. (d and e) The expression of involucrin and loricrin was also detected in HFKs by western blot. Data show mean \pm S.E.M. of triplicate cultures $(n=3)$. Statistical differences were tested with one-way ANOVA followed by a two-tailed $t$-test. Representative images are shown. Scale bar $=10 \mu \mathrm{m}$. ${ }^{*} P<0.05 ;{ }^{* *} P<0.01$.

mechanism underlying the MMP-2 mediation of LCN2 upregulation is unclear, and deserves further study.

In conclusion, this study demonstrated the overexpression of Tcf7l1 and LCN2 in keratinocytes with dysregulated differentiation. Tcf7l1 enhances the expression of MMP-2 in keratinocytes, which further upregulates the level of LCN that correlates closely with differentiation markers. Therefore, LCN2 mediates the Tcf7l1 dysregulation of keratinocyte differentiation. Targeting the Tcf7l1-LCN2 axis may be one of the approaches in managing skin diseases with dysregulated keratinocyte differentiation.

\section{MATERIALS AND METHODS}

Tissue samples

The tissue samples were collected from healthy donors or patients with seborrheic keratosis, psoriasis vulgaris, verrucous epidermal nevus, pigmented nevus, Bowenoid papulosis, BCC, condyloma acuminatum and SCC, who had been diagnosed pathologically but received no therapy within the past 4 weeks (Supplementary Table S1). These samples were processed for paraffin sections, whereas some fresh tissues were surgically dissected of subcutaneous fat before freezing at $-80^{\circ} \mathrm{C} .42$ Based on hematoxylin and eosin staining, SCC samples were graded according to 
a
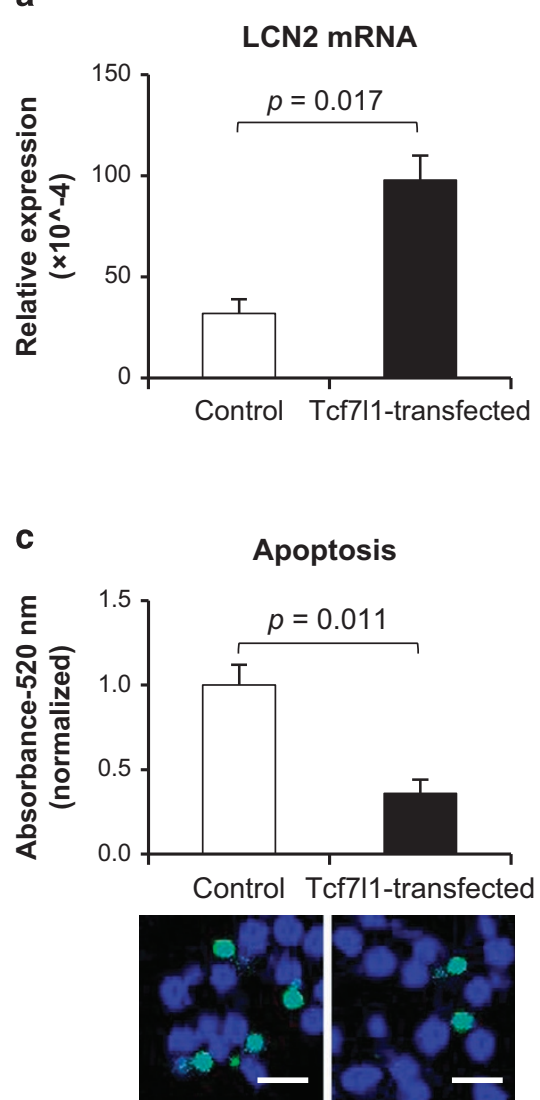

b
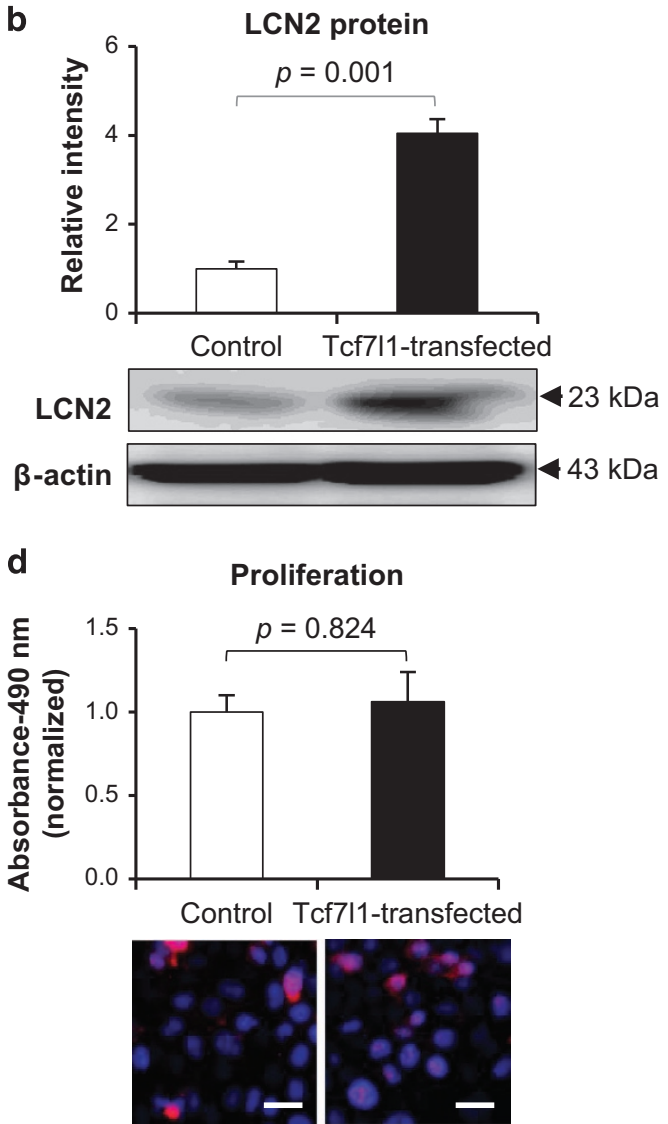

mRNA

$\square$ None

옹 Calcium

$\square$ Tcf7l1

- Calcium + Tcf7l1

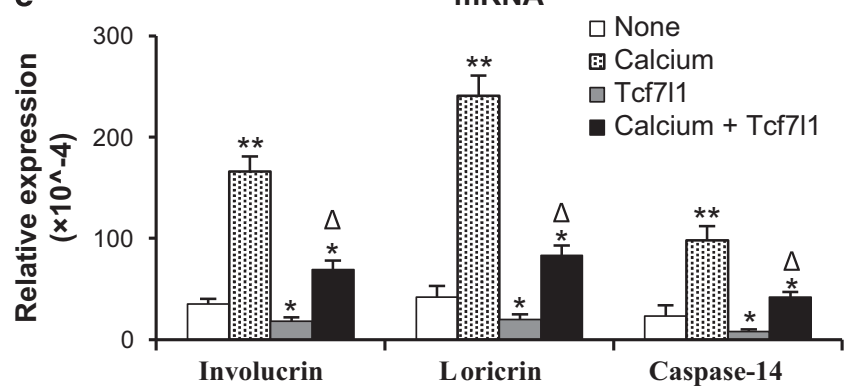

Figure 5. The effect of Tcf7l1 overexpression on HFKs. After the transfection of Tcf7l1-inserted pcDNA vector, HFKs were stimulated with calcium chloride (1.2 mM, 7 days). (a and b) By qRT-PCR (a) and western blot (b), HFKs expressed more lipocalin 2 (LCN2) upon Tcf7l1 pcDNA transfection. (c and $\mathbf{d})$ Both cell apoptosis (c) and proliferation (d) were determined in HFKs that were either transfected with Tcf7l1 pcDNA or not. Cell apoptosis and proliferation were also visualized by TUNEL and fluorescent Ki-67 staining, respectively. (e) qRT-PCR was performed for the mRNA levels of involucrin, loricrin and caspase-14 in HFKs. Data show mean \pm S.E.M. of triplicate cultures $(n=3)$. Statistical differences were tested with one-way ANOVA followed by a two-tailed $t$-test. Scale bar $=10 \mu \mathrm{m}$. In $(\mathbf{e}),{ }^{*} P<0.05,{ }^{* *} P<0.01$, compared with nontreated groups accordingly; ${ }^{\Delta} P<0.05$, compared with calcium alone-treated HFKs accordingly.

Broders' classification: grade I, tumors in which more than $75 \%$ of cells are differentiated; grade II, tumors with $50-75 \%$ differentiation; grade III, tumors with $25-50 \%$ differentiation; and grade IV, tumors with less than $25 \%$ differentiation. ${ }^{43}$ This study was conducted under the supervision of the research ethics committees of the hospitals. Written informed patient consent was obtained before harvesting the tissue samples.

\section{Immunohistochemistry}

As described previously, ${ }^{44}$ paraffin sections were routinely dewaxed, and the antigens were retrieved by using a microwave method. After permeabilization with $0.1 \%$ Triton-100/PBS, sections were blocked with dual endogenous enzymes (DAKO, Glostrup, Denmark) and then incubated with rabbit anti-Tcf7l1 or LCN2 IgG ( $2 \mu \mathrm{g} / \mathrm{ml}$; Santa Cruz, Dallas, TX, USA). Thereafter, the horseradish peroxidase (HRP)-labeled polymer-conjugated goat anti-rabbit IgG (DAKO) was added to sections before the color (brown) development with the 3,3'-diaminobenzidine-chromogen substrate. Finally, the sections were counterstained with Mayer's hematoxylin.

Cell culture and in vitro transfection

SCC-13 cells were grown in Dulbecco's modified eagle media with $10 \%$ FBS. $^{45}$ HFKs were isolated from neonatal foreskin, ${ }^{46}$ and cultured in the same media for SCC-13 cells. The retroviral infection of HPV16 E6/E7 genes was performed on HFKs. ${ }^{46}$ By following a reported method, ${ }^{47}$ human Tcf7l1 cDNA was subcloned into a pDC315 vector (gifted by Dr. Cheng Pan, Wuhan University) and then transfected into HFKs. Using gene-specific PCR primers (Supplementary Table S2), Tcf7l1 cDNA was incorporated with sequences of EcoRl and Nhel, and then ligated into the corresponding restriction enzyme sites in vector. Tcf7l1 overexpression in transfected cells 
were verified by both qRT-PCR and western blot. In some experiments, calcium chloride $(1.2 \mathrm{mM})$, neutralizing anti-LCN2 antibody or isotype control (R\&D Systems, Minneapolis, MN, USA) were added to cultured media.

a

Tcf7I1-HFKs

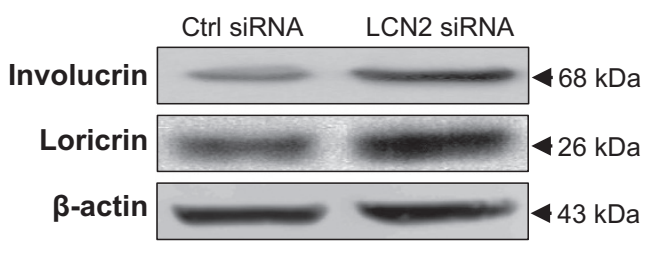

C

\section{E6/E7-HFKs}

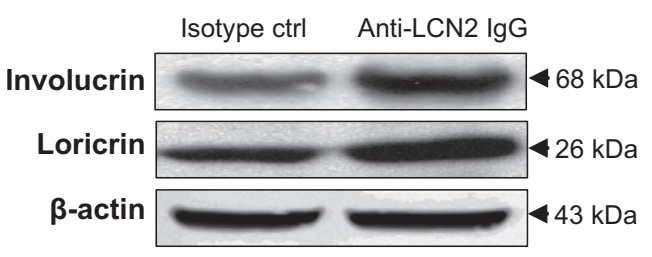

e
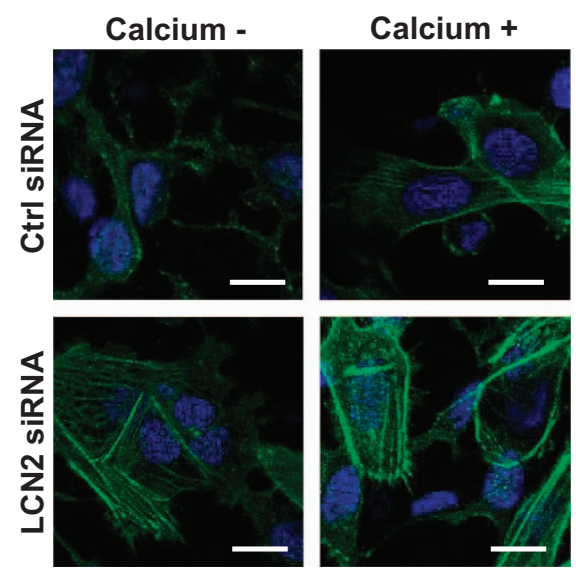

siRNA transfection was carried out as reported previously. ${ }^{48}$ The predesigned Tcf711, LCN2, MMP-2 or control siRNA (Life Technologies, Carlsbad, CA, USA; Supplementary Table S2) was dissolved in a lipofectamine 2000 reagent at a ratio of $10 \mathrm{pmol}$ per $\mu \mathrm{l}$. The final
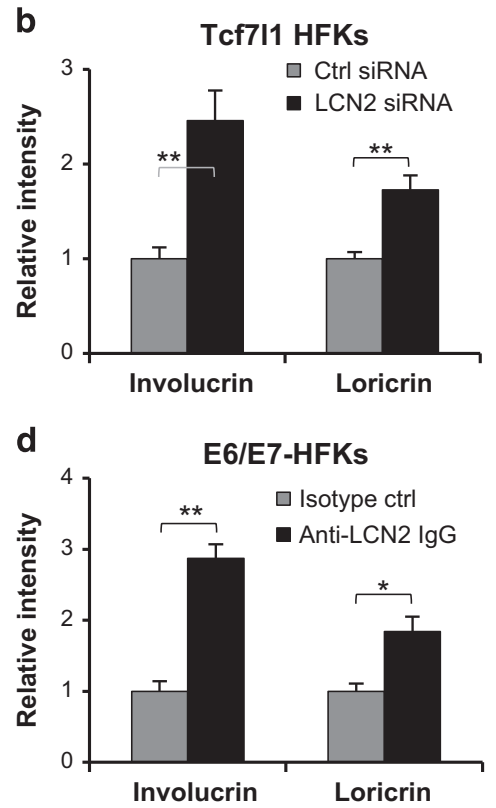

f
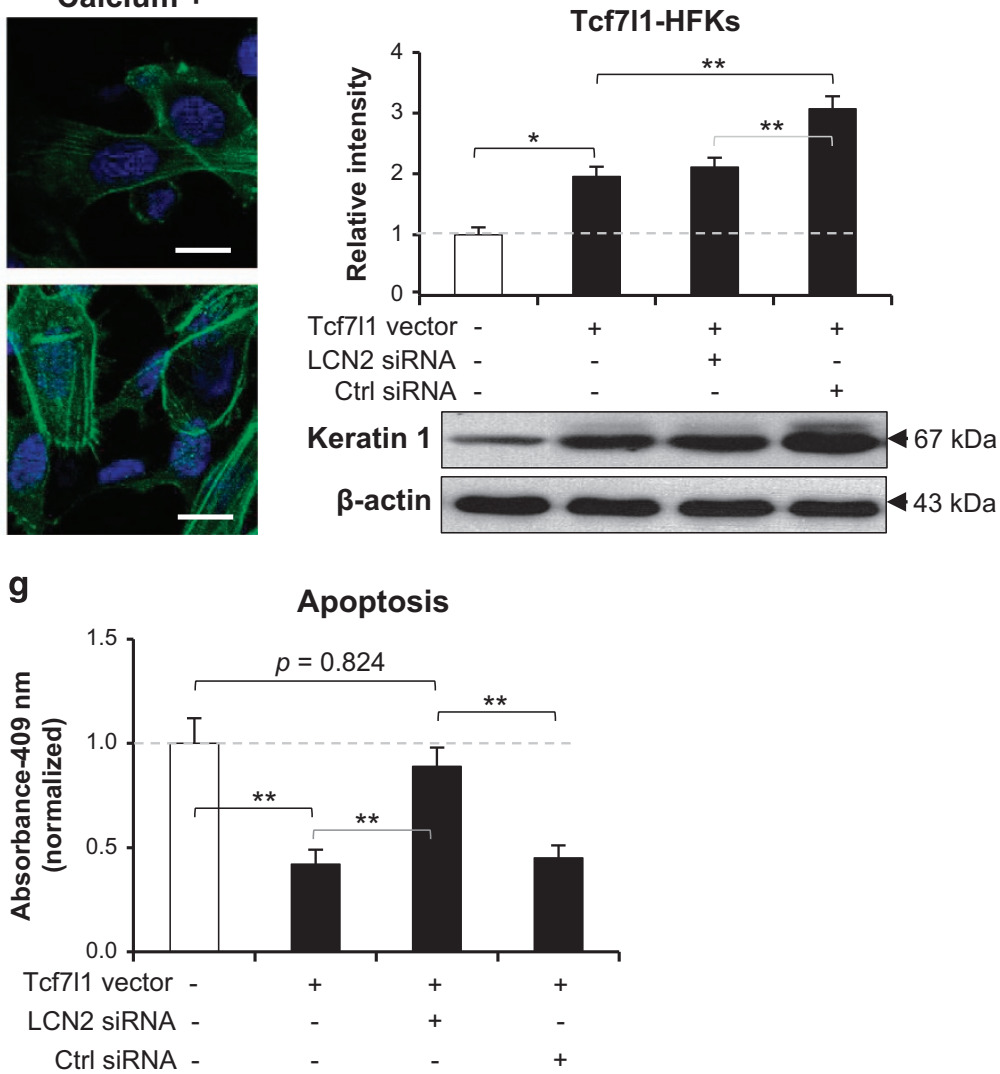

Figure 6. The effect of LCN2 inhibition on HFKs. (a and b) By western blot, involucrin and loricrin expression was determined in Tcf7l1transfected HFKs that were then treated with LCN2 or control siRNA. (c and d) Similarly, involucrin and loricrin were assessed in E6/E7transfected HFKs that were treated with neutralizing anti-LCN2 antibody or isotype control ( $2 \mu \mathrm{g} / \mathrm{ml}, 2$ days). (e and f) By immunofluorescence (e) and western blot (f), keratin 1 was detected in HFKs that were transfected with Tcf7l1 vector and then LCN2 or control siRNA. (g) HFKs were pre-transfected with Tcf7I1 vector, and then transfected with LCN2 siRNA. Cell apoptosis was quantitated by the CaspaTag caspase 3, 7 method. Data show mean \pm S.E.M. of triplicate cultures $(n=3)$. Statistical differences were tested with one-way ANOVA followed by a twotailed $t$-test. Representative images are shown. Scale bar $=10 \mu \mathrm{m}$. ${ }^{*} P<0.05 ;{ }^{* *} P<0.01$. 
a

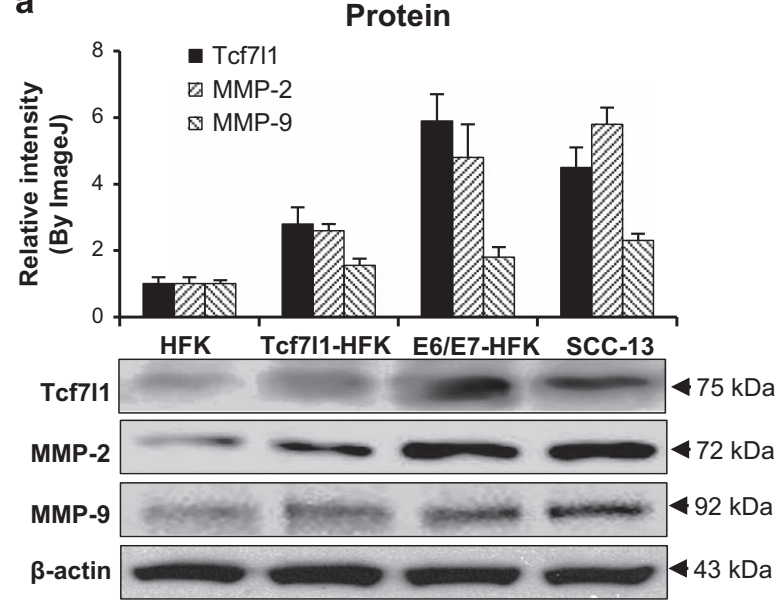

C

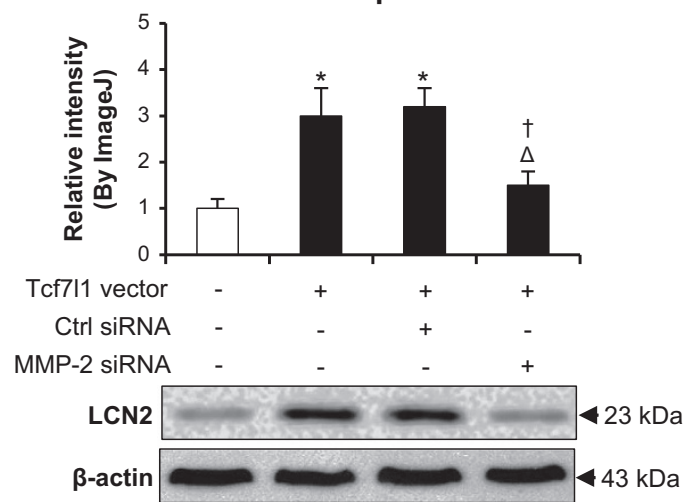

b

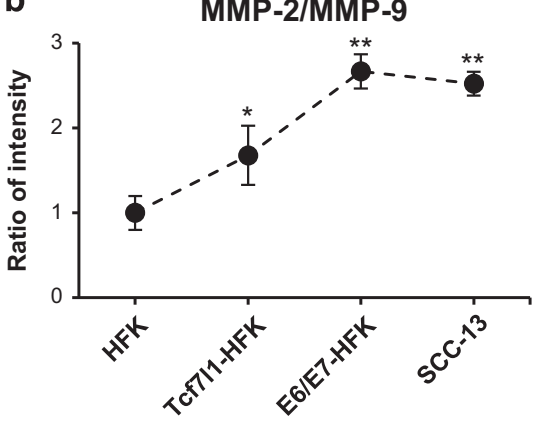

d

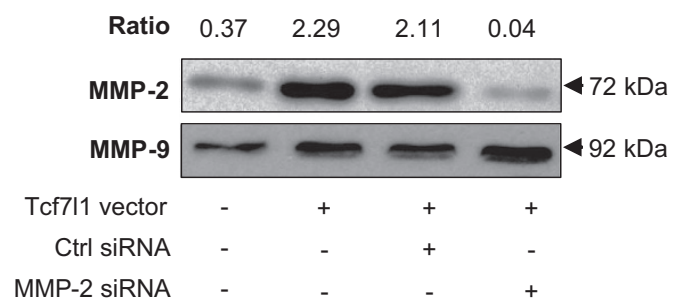

Figure 7. The effect of MMP-2 on LCN2 expression in cells. (a) By western blot, the expression of Tcf7l1, MMP-2 and MMP-9 was determined in SCC-13 cells and Tcf7l1- or E6/E7-transfected HFKs. (b) The ratios of MMP-2 to MMP-9 were calculated by using the relative intensity values from western blot. ${ }^{*} P<0.05,{ }^{* *} P<0.01$, compared with the control HFK group. (c) By western blot, the LCN2 protein was detected in the HFKs that were transfected with Tcf7l1-expressing lentiviral vector or MMP-2/control siRNA. ${ }^{*} P<0.05$, compared with the nontreated group; ${ }^{\Delta} p<0.05$, compared with Tcf7l1 transfection alone group; ${ }^{\dagger} P<0.05$, compared with control siRNA group. (d) The MMP-2 and MMP-9 proteins were blotted in cell lysates that were precipitated by anti-LCN2 IgG-conjugated protein IgG agarose. The ratios mean MMP-2 to MMP-9 values. Data show mean \pm S.E.M. of triplicate cultures $(n=3)$. Statistical differences were tested with one-way ANOVA followed by a two-tailed $t$-test.

concentrations of siRNAs in media were $15 \mathrm{pmol} / \mathrm{ml}$. qRT-PCR was used for verifying such transfection. Cells were used for assays 3 days after transfection.

\section{Immunofluorescence and flow cytometry}

Immunofluorescent detection was performed as described previously. ${ }^{49}$ Cells grown on cover glass were fixed with $4 \%$ paraformaldehyde solution. After blocking, cells were incubated with rabbit anti-Tcf7l1 (fluorescein isothiocyanate-conjugated; Jieqing Co., Wuhan, China) or anti-LCN2 (Alexa Fluor 555-conjugated, Bioss Inc., Woburn, MA, USA) IgG. For confocal analysis, rabbit anti-involucrin (Alexa Fluor 555-conjugated; Bioss), antiloricrin (Cy5-conjugated) (Biorbyt LLC, San Francisco, CA, USA) or anticytokeratin 1 (Alexa Fluor 488-conjugated) (Abcam, Cambridge, MA, USA) antibodies were used by following the standard method. ${ }^{50}$ In flow cytometry, these antibodies were used also but detected in a LSRII instrument (BD Biosciences, San Jose, CA, USA). Data were analyzed using FlowJo7.6.1 software (Tree Star, Ashland, OR, USA).

\section{Cell apoptosis and proliferation}

The apoptosis and proliferation of cells were quantitatively analyzed by using a CaspaTag caspase 3,7 fluorescein assay kit (EMD Millipore, Billerica, MA, USA) and a CellTiter 96 solution (Promega Co., Madison, WI, USA), respectively. ${ }^{42}$ Besides, cell apoptosis and proliferation were visualized by terminal deoxynucleotidyl transferase-mediated dUTP nick end labeling
(Jieqing Co.) and Alexa Fluor 647-labeled Ki-67 staining (Abcam), respectively.

qRT-PCR

qRT-PCR was performed as described previously. ${ }^{51}$ By using PureLink RNA kit (Invitrogen, Grand Island, NY, USA), total RNA was extracted from fresh tissues or cell cultures. Reverse transcription was carried out with a commercial cDNA kit (Applied Biosystems, Carlsbad, CA, USA). Amplification was carried out using the $7900 \mathrm{HT}$ Fast PCR System (Applied Biosystems). SYBR Green Master Mixes (Invitrogen) was used as the fluorescent dye. The sequences of primers (Invitrogen) are listed in Supplementary Table S2.

\section{Western blotting and immunoprecipitation}

Protein lysates were extracted using a RIPA lysis buffer supplemented with a protease inhibitor cocktail (Thermo Scientific, Shanghai, China). Western blot was performed according to a previous protocol. ${ }^{52}$ Proteins were separated by electrophoresis, and then transferred onto polyvinylidene difluoride membranes. The rabbit primary antibodies (all from Santa Cruz) were used, followed by incubation with HRP-labeled goat anti-rabbit IgG (Southern Biotech, Birmingham, AL, USA). Signals were developed with an $\mathrm{ECL}$ kit (Thermo Scientific). All normalized intensities were quantified by Image $\mathrm{J} 1.61 \mathrm{u}$.

For immunoprecipitation, cell lysates were incubated with protein $G$ agarose and anti-LCN2 IgG as described previously. ${ }^{20}$ The bound 
complexes were washed from agarose beads, and then analyzed by western blot at a reducing and denatured condition.

\section{ELISA}

LCN2 in the culture supernatants was detected by using a Quantikine sandwich ELISA kit (R\&D Systems), according to the manufacturer's instruction.

\section{Statistical analysis}

Data were presented as the mean \pm standard error of the mean (S.E.M.). Statistical analysis was performed using the STATA 10.0 software (StataCorp., College Station, TX, USA). ANOVA was used in the comparison of more than two groups. Data were analyzed by one-way ANOVA followed by a two-tailed $t$-test. Linear regression was done for the correlation between the mRNA expression values of Tcf7l1 and LCN2. The differences were considered significant at $P<0.05$.

\section{ABBREVIATIONS}

BCC, basal cell carcinoma; ELISA, enzyme-linked immunosorbent assay; HFK, human foreskin keratinocyte; HPV, human papilloma virus; LCN2, lipocalin 2; MMP, matrix metalloproteinase; qRT-PCR, quantitative real-time polymerase chain reaction; SCC, squamous cell carcinoma; Tcf7l1, transcription factor 7-like 1.

\section{ACKNOWLEDGEMENTS}

This study was partially supported by the Startup Funds of the Second Affiliated Hospital of XJUT and the Fundamental Research Funds for the Central Universities (No. 2015qngz01).

\section{COMPETING INTERESTS}

The authors declare no conflict of interest.

\section{REFERENCES}

1 Cristancho AG, Schupp M, Lefterova MI, Cao S, Cohen DM, Chen CS et al. Repressor transcription factor 7-like 1 promotes adipogenic competency in precursor cells. Proc Natl Acad Sci USA 2011; 108: 16271-16276.

2 Kuwahara A, Sakai H, Xu Y, Itoh Y, Hirabayashi Y, Gotoh Y. Tcf3 represses Wnt- $\beta$ catenin signaling and maintains neural stem cell population during neocortical development. PLoS One 2014; 9: e94408.

3 Zhang X, Gao Y, Lu L, Zhang Z, Gan S, Xu L et al. JmjC domain-containing protein 6 (Jmjd6) derepresses the transcriptional repressor transcription factor 7-like 1 (Tcf7l1) and is required for body axis patterning during xenopus embryogenesis. J Biol Chem 2015; 290: 20273-20283.

4 Nguyen $\mathrm{H}$, Rendl M, Fuchs E. Tcf3 governs stem cell features and represses cell fate determination in skin. Cell 2006; 127: 171-183.

5 Zhao Z, Liu Y, He H, Chen X, Chen J, Lu YC. Candidate genes influencing sensitivity and resistance of human glioblastoma to Semustine. Brain Res Bull 2011; 86: 189-194.

6 Slyper M, Shahar A, Bar-Ziv A, Granit RZ, Hamburger T, Maly B et al. Control of breast cancer growth and initiation by the stem cell-associated transcription factor TCF3. Cancer Res 2012; 72: 5613-5624.

7 Ma H, Mallampati S, Lu Y, Sun B, Wang E, Leng $X$ et al. The Sox4/Tcf7l1 axis promotes progression of BCR-ABL-positive acute lymphoblastic leukemia. Haematologica 2014; 99: 1591-1598.

8 Howard JM, Nuguid JM, Ngole D, Nguyen H. Tcf3 expression marks both stem and progenitor cells in multiple epithelia. Development 2014; 141: 3143-3152.

9 Shah M, Rennoll SA, Raup-Konsavage WM, Yochum GS. A dynamic exchange of TCF3 and TCF4 transcription factors controls MYC expression in colorectal cancer cells. Cell Cycle 2015; 14: 323-332.

10 Barton CE, Johnson KN, Mays DM, Boehnke K, Shyr Y, Boukamp P et al. Novel p63 target genes involved in paracrine signaling and keratinocyte differentiation. Cell Death Dis 2010; 1: e74.

11 Miao Q, Ku AT, Nishino Y, Howard JM, Rao AS, Shaver TM et al. Tcf3 promotes cell migration and wound repair through regulation of lipocalin 2. Nat Commun 2014; 5: 4088.

12 Ferreira AC, Dá Mesquita S, Sousa JC, Correia-Neves M, Sousa N, Palha JA et al. From the periphery to the brain: Lipocalin-2, a friend or foe? Prog Neurobiol 2015; 131: $120-136$.
13 Schmidt-Ott KM, Mori K, Li JY, Kalandadze A, Cohen DJ, Devarajan P et al. Dual action of neutrophil gelatinase-associated lipocalin. J Am Soc Nephrol 2007; 18: 407-413.

14 Kim HJ, Yoon HJ, Yoon KA, Gwon MR, Jin Seong S, Suk K et al. Lipocalin-2 inhibits osteoclast formation by suppressing the proliferation and differentiation of osteoclast lineage cells. Exp Cell Res 2015; 334: 301-309.

15 Chung IH, Chen CY, Lin YH, Chi HC, Huang YH, Tai PJ et al. Thyroid hormonemediated regulation of lipocalin 2 through the Met/FAK pathway in liver cancer. Oncotarget 2015; 6: 15050-15064.

16 Yang J, Bielenberg DR, Rodig SJ, Doiron R, Clifton MC, Kung AL et al. Lipocalin 2 promotes breast cancer progression. Proc Natl Acad Sci USA 2009; 106: 3913-3918.

17 Larsen MT, Häger M, Glenthøj A, Asmar F, Clemmensen SN, Mora-Jensen H et al. miRNA-130a regulates C/EBP- $\varepsilon$ expression during granulopoiesis. Blood 2014; 123 : 1079-1089.

18 Shinriki S, Jono H, Ueda M, Obayashi K, Nakamura T, Ota K et al. Stromal expression of neutrophil gelatinase-associated lipocalin correlates with poor differentiation and adverse prognosis in oral squamous cell carcinoma. Histopathology 2014; 64: 356-364.

19 Nuntagowat C, Leelawat K, Tohtong R. NGAL knockdown by siRNA in human cholangiocarcinoma cells suppressed invasion by reducing NGAL/MMP-9 complex formation. Clin Exp Metastasis 2010; 27: 295-305.

20 Kiczak L, Tomaszek A, Bania J, Paslawska U, Zacharski M, Noszczyk-Nowak A et al. Expression and complex formation of MMP9, MMP2, NGAL, and TIMP1 in porcine myocardium but not in skeletal muscles in male pigs with tachycardia-induced systolic heart failure. Biomed Res Int 2013; 2013: 283856.

21 Bouchet S, Bauvois B. Neutrophil gelatinase-associated lipocalin (NGAL), promatrix metalloproteinase-9 (pro-MMP-9) and their complex pro-MMP-9/NGAL in leukaemias. Cancers (Basel) 2014; 6: 796-812.

22 Dayer C, Stamenkovic I. Recruitment of matrix metalloproteinase-9 (MMP-9) to the fibroblast cell surface by lysyl hydroxylase 3 (LH3) triggers transforming growth factor- $\beta$ (TGF- $\beta$ ) activation and fibroblast differentiation. J Biol Chem 2015; 290: 13763-13778.

23 Liu T, Lin J, Ju T, Chu L, Zhang L. Vascular smooth muscle cell differentiation to an osteogenic phenotype involves matrix metalloproteinase-2 modulation by homocysteine. Mol Cell Biochem 2015; 406: 139-149.

24 Akgül B, Bauer B, Zigrino P, Storey A, Mauch C, Pfister H. Upregulation of lipocalin2 in human papillomavirus-positive keratinocytes and cutaneous squamous cell carcinomas. J Gen Virol 2011; 92: 395-401.

25 Lee JH, Kye KC, Seo EY, Lee K, Lee SK, Lim JS et al. Expression of neutrophil gelatinase-associated lipocalin in calcium-induced keratinocyte differentiation. J Korean Med Sci 2008; 23: 302-306.

26 Mallbris L, O'Brien KP, Hulthen A, Sandstedt B, Cowland JB, Borregaard N et al. Neutrophil gelatinase-associated lipocalin is a marker for dysregulated keratinocyte differentiation in human skin. Exp Dermatol 2002; 11: 584-591.

27 Ogawa E, Owada Y, Ikawa S, Adachi Y, Egawa T, Nemoto K et al. Epidermal FABP (FABP5) regulates keratinocyte differentiation by $13(\mathrm{~S})$-HODE-mediated activation of the NF-KB signaling pathway. J Invest Dermatol 2011; 131: 604-612.

28 Rinnerthaler M, Streubel MK, Bischof J, Richter K. Skin aging, gene expression and calcium. Exp Gerontol 2015; 68: 59-65.

29 Jiang YJ, Kim P, Uchida Y, Elias PM, Bikle DD, Grunfeld C et al. Ceramides stimulate caspase-14 expression in human keratinocytes. Exp Dermatol 2013; 22: 113-118.

30 Nagarajan P, Chin SS, Wang D, Liu S, Sinha S, Garrett-Sinha LA. Ets1 blocks terminal differentiation of keratinocytes and induces expression of matrix metalloproteases and innate immune mediators. J Cell Sci 2010; 123: 3566-3575.

31 Kataoka S, Hattori K, Date A, Tamura H. Human keratinocyte caspase-14 expression is altered in human epidermal 3D models by dexamethasone and by natural products used in cosmetics. Arch Dermatol Res 2013; 305: 683-689.

32 Fernandez-Flores A. Small lesions of porokeratosis show a normal proliferation rate with MIB-1. Acta Dermatovenerol Alp Pannonica Adriat 2008; 17: 22-25.

33 Lin HY, Kao CH, Lin KM, Kaartinen V, Yang LT. Notch signaling regulates late-stage epidermal differentiation and maintains postnatal hair cycle homeostasis. PLOS One 2011; 6: e15842.

34 Beck IM, Müller M, Mentlein R, Sadowski T, Mueller MS, Paus R et al. Matrix metalloproteinase-19 expression in keratinocytes is repressed by transcription factors Tst-1 and Skn-1a: implications for keratinocyte differentiation. J Invest Dermatol 2007; 127: 1107-1114.

$35 \mathrm{Kim} \mathrm{JH}, \mathrm{Kim} \mathrm{JH}, \mathrm{Cho} C \mathrm{~S}$, Jun HO, Kim DH, Yu YS et al. Differential roles of matrix metalloproteinase- 9 and -2 , depending on proliferation or differentiation of retinoblastoma cells. Invest Ophthalmol Vis Sci 2010; 51: 1783-1788.

36 Gweon EJ, Kim SJ. Resveratrol attenuates matrix metalloproteinase-9 and -2regulated differentiation of HTB94 chondrosarcoma cells through the p38 kinase and JNK pathways. Oncol Rep 2014; 32: 71-78. 
37 Xue M, Jackson CJ. Autocrine actions of matrix metalloproteinase (MMP)-2 counter the effects of MMP-9 to promote survival and prevent terminal differentiation of cultured human keratinocytes. J Invest Dermatol 2008; 128: 2676-2685.

38 Hiromoto T, Noguchi K, Yamamura M, Zushi Y, Segawa E, Takaoka K et al. Upregulation of neutrophil gelatinase-associated lipocalin in oral squamous cell carcinoma: relation to cell differentiation. Oncol Rep 2011; 26: 1415-1421.

39 Piamya P, Tiantong A, Chen SE, Liu WB, Yu C, Nagahata $\mathrm{H}$ et al. Fingerprinting of gelatinase subtypes for different topographic regions on non-retaining placenta of Holstein cows. Animal 2015; 9: 490-499.

40 Folkesson M, Kazi M, Zhu C, Silveira A, Hemdahl AL, Hamsten A et al. Presence of NGAL/MMP-9 complexes in human abdominal aortic aneurysms. Thromb Haemost 2007; 98: 427-433.

41 Chakraborty S, Kaur S, Guha S, Batra SK. The multifaceted roles of neutrophil gelatinase associated lipocalin (NGAL) in inflammation and cancer. Biochim Biophys Acta 2012; 1826: 129-169.

42 Zou XY, Ding D, Zhan N, Liu XM, Pan C, Xia YM. Glyoxalase I is differentially expressed in cutaneous neoplasms and contributes to the progression of squamous cell carcinoma. J Invest Dermatol 2015; 135: 589-598.

43 Goldenberg G. Histopathology of skin cancer. In: Stockfleth E, Rosen T, Shumack S (eds). Managing Skin Cancer. Springer Press: Berlin, 2010, pp 17-35.

44 Cheng H, Zhan N, Ding D, Liu X, Zou X, Li K et al. HPV type 16 infection switches keratinocytes from apoptotic to proliferative fate under TWEAK/Fn14 interaction. J Invest Dermatol 2015; 135: 2427-2436.

45 Rohani MG, Pilcher BK, Chen P, Parks WC. Cdc42 inhibits ERK-mediated collagenase-1 (MMP-1) expression in collagen-activated human keratinocytes. $J$ Invest Dermatol 2014; 134: 1230-1237.

46 Guerrini JS, Bouvard V, Oswald E, Alonso A, Prétet JL, Tommasino M et al. E6 and E7 proteins from different beta-papillomaviruses types do not interfere in UVB-induced apoptosis of HaCaT keratinocytes. Exp Dermatol 2011; 20: 71-73.

47 Li L, Dong X, Leong MC, Zhou W, Yang Z, Chen F et al. Identification of the novel protein FAM172A, and its up-regulation by high glucose in human aortic smooth muscle cells. Int J Mol Med 2010; 26: 483-490.

48 Xia Y, Herlitz LC, Gindea S, Wen J, Pawar RD, Misharin A et al. Deficiency of fibroblast growth factor-inducible 14 (Fn14) preserves the filtration barrier and ameliorates lupus nephritis. J Am Soc Nephrol 2015; 26: 1053-1070.

49 Zhang $\mathrm{Y}$, Yang J, Jiang S, Fang C, Xiong L, Cheng $\mathrm{H}$ et al. The lupus-derived antidouble-stranded DNA IgG contributes to myofibroblast-like phenotype in mesangial cells. J Clin Immunol 2012; 32: 1270-1278.

50 Xia Y, Zhang Y, Jiang S, Cheng H. CD4+ T-cell anergy induced by lin- CD117(c-kit)+ stem cell-derived immature dendritic cells loaded with nuclear antigen derived from Trypanosoma equiperdum. Autoimmunity 2010; 43: 664-671.

51 Xia Y, Campbell SR, Broder A, Herlitz L, Abadi M, Wu P et al. Inhibition of the TWEAK/Fn14 pathway attenuates renal disease in nephrotoxic serum nephritis. Clin Immunol 2012; 145: 108-121.

52 Zou X, Cheng H, Zhang Y, Fang C, Xia Y. The antigen-binding fragment of antidouble-stranded DNA lgG enhances F-actin formation in mesangial cells by binding to alpha-actinin-4. Exp Biol Med (Maywood) 2012; 237: 1023-1031.

\section{(c) (i)}

This work is licensed under a Creative Commons Attribution 4.0 nternational License. The images or other third party material in this article are included in the article's Creative Commons license, unless indicated otherwise in the credit line; if the material is not included under the Creative Commons license, users will need to obtain permission from the license holder to reproduce the material. To view a copy of this license, visit http://creativecommons.org/licenses/ by/4.0/

Supplemental Information accompanies the paper on the Cell Death and Discovery website (http://www.nature.com/cddiscovery) 